\title{
REFLEXÕES, CONTORNOS, TRILHAS DE APRENDIZAGEM E RESULTADOS DA UTILIZAÇÃO DE METODOLOGIAS ATIVAS NO ENSINO HÍBRIDO
}

\author{
FRANCA/SP MAIO/2018
}

\author{
Carmen Lucia Tozzi Mendonça Conti - Unifran - carmen.conti@unifran.edu.br \\ Katiucia e silva - Unifran - katiucia.silva@unifran.edu.br \\ Márcia Pereira Cabral - Unifran - marcia.cabral@unifran.edu.br
}

Tipo: Relato de Experiência Inovadora (EI)

Categoria: Métodos e Tecnologias

Setor Educacional: EDUCAÇÃO SUPERIOR

\begin{abstract}
RESUMO
O presente trabalho tem como objetivo apresentar um relato de experiência sobre a implantação do ensino híbrido, pela Universidade Cruzeiro do Sul Virtual, aplicado no Curso de Licenciatura em Pedagogia, ofertado na modalidade a Distância. A iniciativa, surge para acompanhar as tendências educacionais e também para atender os novos desafios do século XXI, o desenvolvimento de competências e habilidades que contribuam para resolução de problemas, a preparação para 0 exercício da cidadania e busca de inovação educacional. O modelo de ensino híbrido implantado conta com a utilização do ambiente virtual de aprendizagem Blackboard, com encontros presenciais semanais a partir da aplicação de metodologias ativas por parte do educador. Esta tomada de decisão aponta para a compreensão de um novo aluno, agente responsável e autônomo em seu processo de aprendizagem. Uma das relevâncias que podemos encontrar nesta opção de processo educativo, passa pela necessidade e exercício de integralizar conteúdos teóricos e práticos. Assim, pretendemos contribuir com novas reflexões e práticas educacionais que realmente promovam o embarque e engajamento destes agentes em seu processo. Além disso, entendemos que a medida em que 0 conteúdo teórico se mistura na resolução de situações problemas, nos encontramos na direção da criatividade e busca de inovação de forma ampla e objetivada.
\end{abstract}

Palavras-chave: Ensino Híbrido; Metodologias Ativas; Autonomia do processo educativo.

\section{AGRADECIMENTOS}

AGRADECEMOS A PRÓ-REITORIA DE EDUCAÇÃO A DISTÂNCIA DA UNIVERSIDADE CRUZEIRO DO SUL VIRTUAL, PELO INCENTIVO A INVESTIGAÇÃO, PESQUISA E CONSTANTE INOVAÇÃO. 


\section{Introdução}

A produção do conhecimento está em constante evolução, o que gera diversas transformações sociais, econômicas e tecnológicas, e que possibilita uma grande expansão da informação a nível global, a produção desse conhecimento traz impactos significativos na educação como também na cidadania.

A educação atual visa emancipar o indivíduo, e gerar resultados sociais, com pressupostos para desenvolver e construir uma cidadania para que sejam capazes de adaptar-se a novos estilos de trabalho e de tecnologia. Nesta concepção, a tecnologia na educação tende a exercer um papel decisivo na relação educação e cidadania, pois esta proporciona a informação instantânea, com um processo de inovação disruptiva, provocando uma ruptura com padrões já estabelecidos, e isto gera novos conceitos e modelos de ensino- aprendizagem. Destaca-se como condição importante na busca de novos modelos educacionais, as metodologias ativas, que colocam o aluno como agente ativo do próprio processo de aprendizagem, proporcionando a autonomia. E considerando essa condição na busca de novos modelos educacionais, a Cruzeiro do Sul Virtual, viabiliza o processo de autonomia dos seus alunos, com a implantação de metodologias ativas, por meio do ensino híbrido, que possibilita uma aprendizagem dinâmica, onde uma das principais ações refere-se ao processo de mudança no papel do professor.

Diante do processo ensino aprendizagem, este passa a ser um agente mediador do processo de gestão do conhecimento e todas as ações de busca de novas formas de resolver problemas e compreender a aplicação dos conceitos. A proposta didática ocorre com uma interligação de aprendizagem e experiências, visando favorecer a troca de conhecimentos, com o desenvolvimento de competências e habilidades alinhado ao uso da tecnologia para potencializar a aprendizagem. Além disso,o aluno como centro de todo o processo ensino aprendizagem, é o agente responsável pelo construção do próprio conhecimento, devido há uma exigência maior, quanto as construções mentais, como leitura, compreensão, seleção e obtenção de informação, análise e resolução de situações problemas.

\section{Objetivos}

Relatar e ampliar a reflexão sobre novas formas de aplicação de conceitos na busca de qualidade e utilização de recursos inovadores na Educação.

\section{Referencial Teórico}


A educação na atualidade ocupa-se de um novo modelo transformador e inovador, que visa desenvolver habilidades e competências, em especial para os desafios do século XXI, que inclui resolução de problemas e situações cotidianas, torna-se efetivo a adoção de um ensino híbrido diante destas novas exigências inovadoras de educação. Assim, de acordo com Bacich (2015), este modelo propõe que seja repensado a organização da sala de aula, a elaboração do plano pedagógico e a gestão do tempo na escola.

Repensar o modelo de educação, inclui também refletir sobreo papel da educação em preparar os indivíduos, com um projeto pedagógico que alterne e promova a integração de conhecimentos teóricos e práticos, pois somente assim, será possível uma formação integral, com indivíduos engajados em um mundo melhor, e empáticos às questões coletivas

Em uma perspectiva educacional, onde a formação deve enfatizar a formação em cidadania, esta deve pautar-se na construção de desenvolvimento de um pensamento crítico, inovador e criativo, diante das questões da vida real, com engajamento em questões sociais, que promovam mudanças que envolvam o ambiente educacional e social como um todo. SegundoChristensen (2013), o ensino híbrido está emergindo como uma inovação sustentável em relação a sala de aula tradicional, modelo este utilizado principalmente em educação a distância, que alterna encontro presencial com atividades on line através dos ambientes de aprendizagem virtual, o grande destaque deste modelo é possibilidade de interatividade e o aluno protagonista do seu próprio aprendizado.

De acordo, com Espindola (2016), a aprendizagem deve ser resultante de um processo interativo:

\footnotetext{
A ideia é que após o aluno absorver o conteúdo através do meio virtual, ao chegar na sala de aula presencial ele estará ciente do assunto a ser desenvolvido, sendo o local ideal para dar início a interação professor-aluno sanando todas as dúvidas e construindo atividades em grupo, por exemplo.
}

O ensino híbrido substitui espaços escolares convencionais de aprendizagem, destacase ainda o modelo segundo Bacich (2015), por rotação por estações, laboratório rotacional e sala de aula invertida, espaços estes que proporcionam aprender com os pares.Ainda de acordo com a autora, a aprendizagem é mais significativa, quando há um objetivo comum a ser alcançado pelo grupo, e neste modelo a tecnologia é auxiliar no processo de ensino aprendizagem e o professor mediador da construção e desenvolvimento da autonomia dos alunos, orientando e conduzindo a conhecimentos onde o aluno é protagonista de todo o processo, e conta também com a aprendizagem em pares, o que torna o conhecimento colaborativo. 
A Unesco (2015), destaca que o mais importante é que a educação proporcione o sentimento de pertencimento, este pode ser descrito como um objetivo que une os indivíduos distintos, por alguma causa, valores e conceitos.

\section{Procedimentos metodológicos}

No ano de 2018, a Cruzeiro do Sul Virtual, implantou com a prática o Ensino híbrido. A partir de um público de alunos matriculados no primeiro semestre do curso de Pedagogia- Educação a distância (EAD), criou-se condições de repensar a prática de sala de aula na busca de melhor aproximação da teoria e da prática. Os alunos alternaram a aprendizagem por meio do uso da tecnologia do ambiente virtual de aprendizagem - Blackboard e encontro presenciais, uma vez por semana. Isto porque, a proposta é que o aluno se torna um agente ativo no processo de aprendizagem, engajado na construção do conhecimento.

O ambiente virtual de aprendizagem, ofereceu como possibilidades: material didático, vídeo - aulas, exercícios, fóruns, "fale com o tutor" e o calendário para gestão do tempo de estudo e prazos.

O encontro presencial, com docente em sala de aula, proporcionou a possibilidade de contextualizar o conteúdo estudado previamente, com estudo de casos e situações problemas, discutidos em pares ou em grupos.

O professor assumiu a posição demediador do processo de aprendizagem, voltando-se à integração dos conteúdos teóricos e práticos, sempre conduzindo a atividades reflexivas, através das ações de:

- Acolhimento;

- Contextualização,

- Aproximação teoria e Prática,

- Aplicação e resgate do conceito.

- Aplicação prática dos conteúdos.

Assim, durante todo o tempo, os alunos foram orientados a buscar conhecimento prévio no ambiente virtual de aprendizagem e estabelecer relações com outros conceitos para 
posteriormente entrar em processo de discussão e busca de uma reflexão/conclusão.

\section{Apresentação e discussão dos resultados}

O ensino híbrido do curso de Pedagogia - EAD, possibilitou diversas oportunidades de aprendizagem, em especial em momentos que alternou o processo de aprendizagem online com as atividades presenciais. A tecnologia por meio do ambiente virtual de aprendizagem, reorganizou o espaço e tempo em sala de aula, onde foi possível desenvolver um dos principais desafios da educação que é a autonomia. Neste sentido, o aluno buscou conhecimento, desenvolveu a autoaprendizagem, realizou atividades com ferramentas digitais, e aprendeu em pares. Na figura 01, é exemplificada a proposta, os recursos e as possibilidades do ensino híbrido que ocorreu neste processo de ensino-aprendizagem.

\section{Metodologia do Ensino Híbrido}

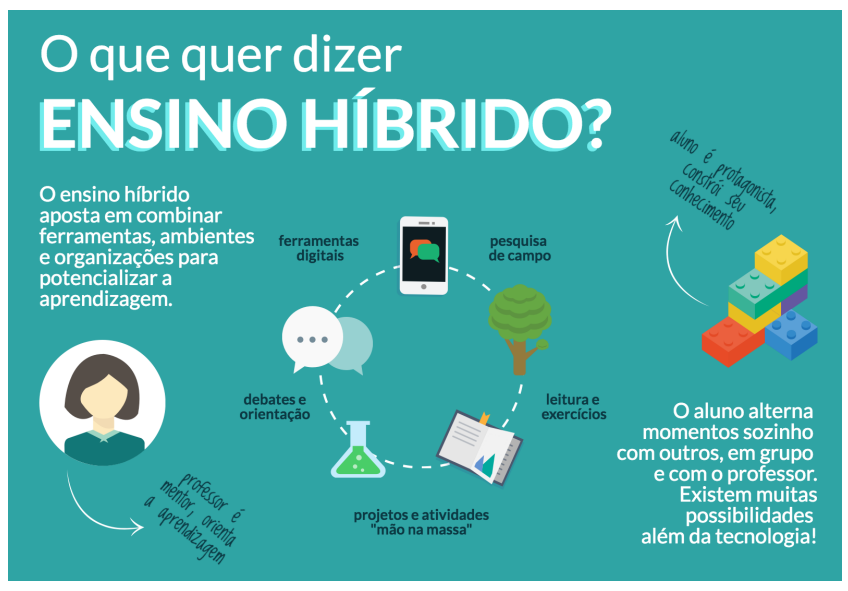

Fonte: Ensino híbrido: O que é e como coloca-lo em prática. Lorenzoni, Marcela. http://info.geekie.com.br/ensino-hibrido/

O aluno, nessa nova metodologia, adotou um perfil ativo na construção do conhecimento, através do estudo e exercícios disponibilizados no ambiente virtual de aprendizagem e foi possível a leitura de material, resolução de exercícios, acesso instantâneo ao resultado das atividades avaliativas, podendo se autoavaliar, de acordo com o resultado das atividades realizadas na forma online. Outro fator preponderante, foi o acesso e contato prévio com o conteúdo apresentado em sala de aula.

$\mathrm{Na}$ figura 02, é apresentado o ambiente virtual de aprendizagem, ferramenta utilizada pelo aluno para acesso ao material didático, realização das atividades online e conhecimento prévio do conteúdo dos encontros presenciais. 
02. Ambiente virtual de aprendizagem

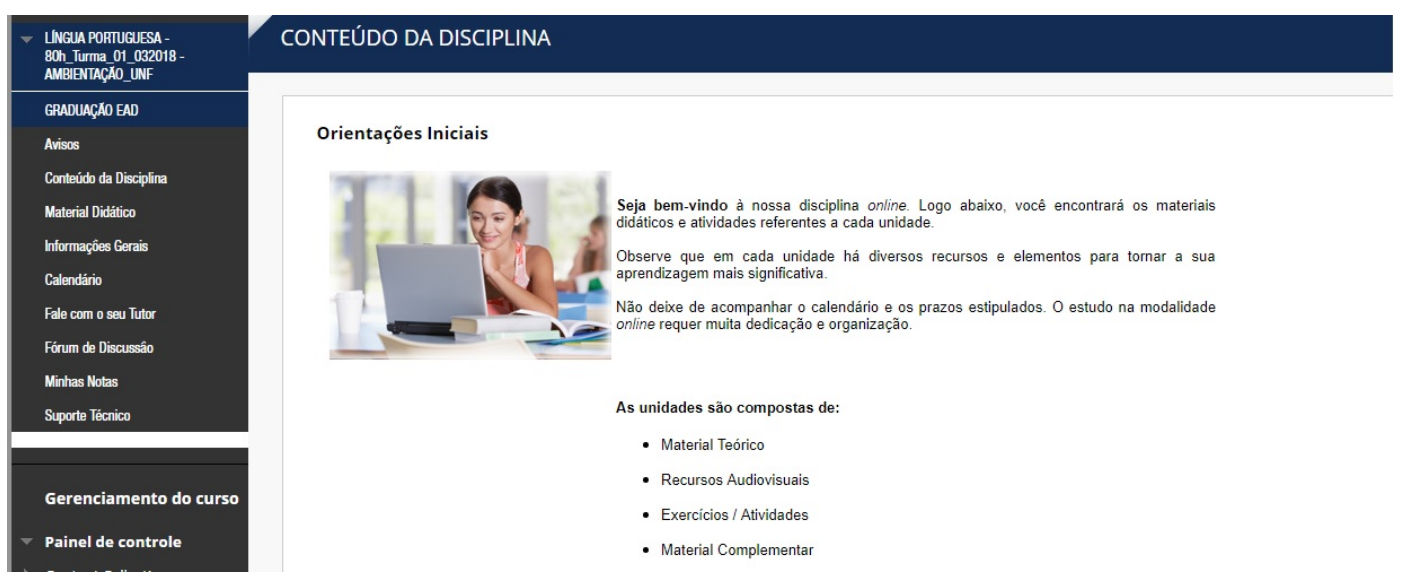

Fonte: Blackboard. Conteúdo da Disciplina- Cruzeiro do Sul Virtual.

Neste sentido, o papel do professor demonstrou favorecer uma nova identidade ao grupo que se envolveu de forma mais criativa e inovadora. Por outro lado, este encontrase em momento de necessidade de revisão do próprio saber sobre o manejo em sala de aula. Mesmo assim, foi possível perceber uma mudança significativa no papel do professor, em encontros presencias com os alunos, este assumiu uma nova conduta de mediador frente a essa nova metodologia.

A figura 03, de acordo com o Inep (2016), aponta para números de matrículas em cursos de graduação, por modalidade de ensino no Brasil - 2006-2016, através deste é possível observar o crescimento da educação a distância, e para atender de forma sustentável e com qualidade a demanda, faz-se necessário o aperfeiçoamento de metodologias, em questão o ensino híbrido para atender as novas exigências educacionais.

03. Crescimento da educação a distância

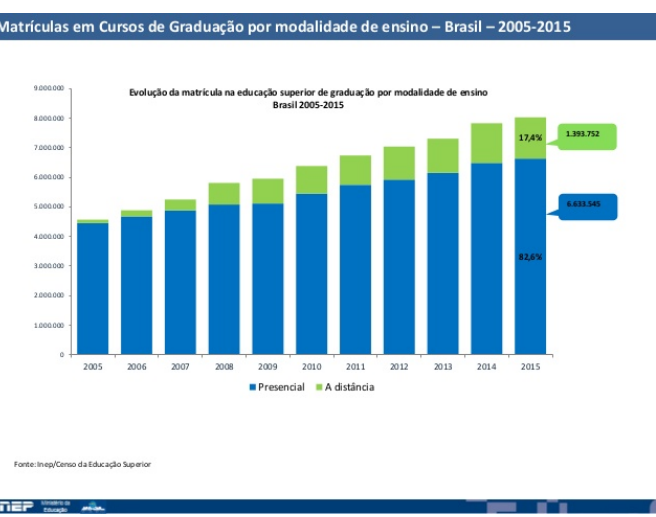

Fonte: Inep (2016), Censo Educação Superior. 
Desta forma, é possível avaliar que o ensino híbrido, atende aos novos desafios do século XXI, e também ao novo perfil de estudantes mais ativo.

\section{Considerações finais}

O ensino híbrido mostrou-se como promissor e aponta para tendência inovação para está modalidade de ensino, o mesmo revoluciona a educação tradicional, para um ensino dinâmico e que busca sentido em suas propostas de práticas pedagógicas. Os pontos positivos do ensino híbrido, são as possibilidades de personalização do ensino, no ambiente virtual de aprendizagem, cada aluno pode focar e ampliar determinados conteúdos de interesse, refazer exercícios, acompanhar o seu próprio desenvolvimento de acordo com os resultados obtidos nas atividades.

E os pontos positivos dos encontros presencias, são a troca de conhecimento com pares, o que propicia uma conexão do grupo, a resolução de situações problemas, o desenvolvimento de habilidades e competências, em especial o desenvolvimento de um pensamento crítico, que o prepara para os desafios profissionais e cotidianos.

\section{Referências}

Aguiar, lana Assunção de; Passos, Elizete. A Tecnologia Como Caminho Para Uma Educação Cidadã. Disponível em acesso 20 de abril de 2018.

Bacich Lilian; Moran, José. Aprender e ensinar com foco na educação híbrida. Revista Pátio, no 25, junho, 2015, p. 45-47. Disponível em: < http://www.grupoa.com.br/r evistapatio/artigo/11551/aprender-e-ensinar-com-foco-na-educacao-hibrida.aspx> acesso 20 de abril de 2018.

BACICH, L.; TANZI NETO, A.; TREVISANI, F. de M. (Orgs.) Ensino Híbrido: Personalização e Tecnologia na Educação. Porto Alegre: Penso, 2015. 270p.

Blackboard. Cruzeiro do Sul Virtual Educação a Distância. Dispónivel em: < https://bb .cruzeirodosulvirtual.com.br/webapps/blackboard/content/listContent.jsp?course_id=_51 6844_1\&content_id=_3652847_1> acesso 20 de abril de 2018.

Christensen, Clayton M; Horn, Michael B, Staker, Heather. Ensino Híbrido: uma Inovação Disruptiva? Uma introdução à teoria dos híbridos. traduzido para o Português por Fundação Lemann e Instituto Península. 2013. Disponível em acesso 20 de abril de 2018. 
ESPÍNDOLA, Rafaela. Como funciona a sala de aula invertida. 2016. Disponível em acesso: 20 de abril de 2018.

Inep- Instituto Nacional de Estudos e Pesquisas Educacionais Anísio Teixeira. Censo da Educação Superior, 2016. Disponível em acesso 05 de maio de 2018.

SOUZA, Cacilda da Silva; IGLESIAS, Alessandro Giraldes; PAZIN-FILHO, Antonio. Estratégias inovadoras para métodos de ensino tradicionais - aspectos gerais. Medicina, v. 47, n. 3, 2014. 